\title{
A nomogram for obtaining the partial pressure of oxygen in alveolar air
}

\author{
Amod Karnik, Dilip R Karnad
}

\section{Medical Intensive}

Care Unit,

Department of

Medicine, King

Edward Memorial

Hospital, Parel,

Bombay 400 012, India

A Karnik

D R Karnad

Reprint requests to:

Dr D R Karnad

Received 20 August 1991

Returned to authors

18 Decembar 1991

Revised version received

Revised version r

Accepted 4 February 1992

Nomogram based on the alveolar gas equation for obtaining the alveolar partial pressure of oxygen $\left(\mathrm{PAO}_{2}\right) . \mathrm{PIO}_{2}$-partial pressure of oxygen in inspired air; $\mathrm{PaCO}_{2}-$ partial pressure of carbon dioxide in arterial blood. Correction for the respiratory quotient $(R)$ : The correction factor is obtained by rounding off $\mathrm{PaCO}_{2}$ in $\mathrm{kPa}$ to the nearest whole number and then dividing this by 10, or by dividing $\mathrm{PaCO}_{2}$ in $\mathrm{mm} \mathrm{Hg}$ by 10 and rounding this off to the nearest whole number. If $R=0.8$, no change in $\mathrm{PAO}_{2}$ is required; if $R=0.7,1.5$ times the correction factor is subtracted from the $\mathrm{PAO}_{2}$ if $R=0.9,1.5$ times the correction factor is added to $P_{A O}$; if $R=1$, twice the correction factor is added to the $\mathrm{PAO}_{2}$
The relation between the arterial and the alveolar partial pressure of oxygen $\left(\mathrm{Po}_{2}\right)$ is used for estimation of venous admixture in critically ill patients, ${ }^{12}$ for adjusting the inspired oxygen concentration to obtain the required arterial $\mathrm{PO}_{2}$ in patients having mechanical ventilation, ${ }^{3-5}$ as a basis for deciding whether to wean a patient from mechanical ventilation, ${ }^{6}$ for calculating intrapulmonary shunting, ${ }^{7}$ and for predicting the extent of hypoxaemia during an air flight in patients with chronic obstructive lung disease. ${ }^{8}$ Whereas the arterial $\mathrm{Po}_{2}$ is estimated by blood gas analysis, the partial pressure of oxygen in alveolar gas $\left(\mathrm{PAO}_{2}\right)$ is obtained from the alveolar gas equation ${ }^{910}$ :

$$
\mathrm{PAO}_{2}=\left(\mathrm{PB}-\mathrm{PH}_{2} \mathrm{O}\right) \times \mathrm{FIO}_{2}-\frac{\mathrm{PaCO}_{2}}{\mathrm{R}},
$$

where $\mathrm{PB}_{\mathrm{B}}$ is the barometric pressure in $\mathrm{mm} \mathrm{Hg}, \mathrm{PH}_{2} \mathrm{O}$ is the water vapour pressure (which at $37^{\circ} \mathrm{C}$ is $47 \mathrm{~mm} \mathrm{Hg}$ ), $\mathrm{FIO}_{2}$ is the fraction of oxygen in inspired air, $\mathrm{PaCO}_{2}$ is the partial pressure of carbon dioxide in arterial blood, and $R$ is the respiratory quotient. To avoid the tedious task of repeatedly calculating $\mathrm{PAO}_{2}$ by solving the alveolar gas equation, we attempted to produce a nomogram that takes all these variables into account.

\section{The nomogram}

The nomogram was drawn on the basis of the alveolar gas equation on the assumption that the value of $R$ is 0.8 . The barometric pressure $(\mathrm{PB})$ is selected on the scale at the bottom of the left hand portion of the nomogram. A vertical line is plotted upwards from this $P_{B}$ until it intersects the desired $\mathrm{FIO}_{2}$ line. For values of $\mathrm{FIO}_{2}$ that lie between two drawn $\mathrm{FIO}_{2}$ lines a measured or approximate point is selected. From this point a horizontal line is

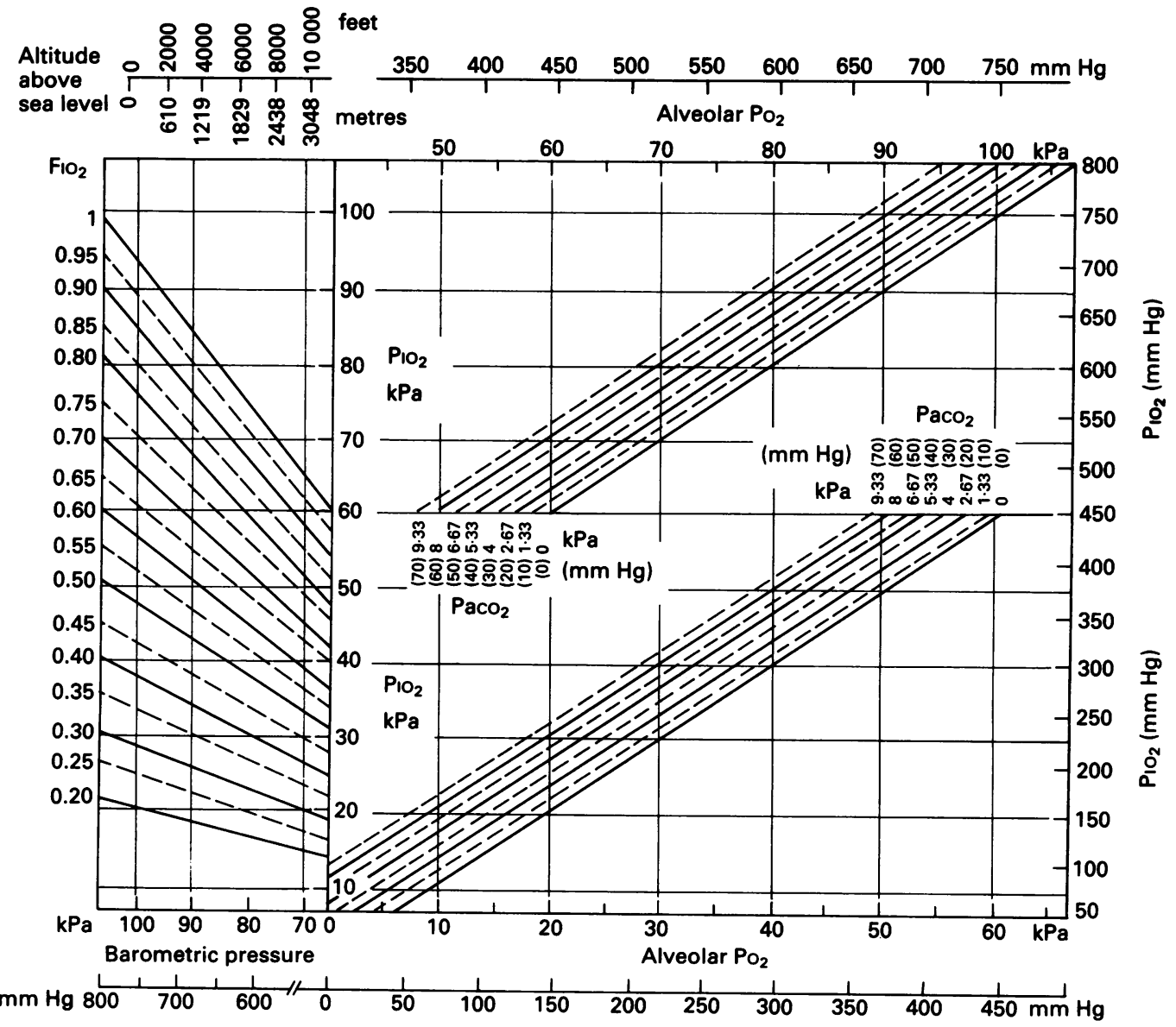


plotted, extending rightwards across the vertical scale for the partial pressure of oxygen in inspired air $\left(\mathrm{PIO}_{2}, \mathrm{kPa}\right)$ into the right hand portion of the nomogram. The $\mathrm{PIO}_{2}$ value may be read off this vertical $(\mathrm{kPa})$ scale or off the vertical scale on the right in $\mathrm{mm} \mathrm{Hg}$ if desired, but is not essential for obtaining the $\mathrm{PAO}_{2}$. The horizontal line that is being plotted is extended until it intersects the desired $\mathrm{PaCO}_{2}$ line. A vertical line through this point of intersection, drawn upwards (if the horizontal line is in the upper half of the nomogram) or downwards (if the horizontal line is in the lower half of the nomogram) will give the $\mathrm{PAO}_{2}$ value in $\mathrm{kPa}$ and $\mathrm{mm} \mathrm{Hg}$.

In most clinical circumstances the respiratory quotient is assumed to be $0 \cdot 8^{37}$; we therefore assumed this value when preparing the nomogram. If, however, in a particular patient the respiratory quotient is measured and is not $0 \cdot 8$, a correction is provided (see legend below figure).

\section{Validation}

After some practice in using the nomogram and a non-programmable pocket calculator, 20 resident doctors were given 10 problems; in each case values were provided for $\mathrm{PB}, \mathrm{FIO}_{2}$, and $\mathrm{PaCO}_{2}$, from which the $\mathrm{PAO}_{2}$ had to be derived first with the calculator and then with the nomogram. In problems 1-5 there was a constant $\mathrm{PB}$ of $760 \mathrm{~mm} \mathrm{Hg}$, so these values could be plotted on the vertical line already drawn on the nomogram at $760 \mathrm{~mm} \mathrm{Hg}$. In problems 6-10 the $P_{B}$ varied from 500 to $800 \mathrm{~mm} \mathrm{Hg}$. These doctors took an average of 13 seconds (95\% CI 8.07-18.03 seconds) longer over each problem with the nomogram than with the calculator. The mean of the residuals (difference between actual and nomogram values) was $7.4 \mathrm{~mm} \mathrm{Hg}$ or $1 \mathrm{kPa}$ $(95 \% \mathrm{CI} 6 \cdot 1-8.7 \mathrm{~mm} \mathrm{Hg}$ or $0.8-1 \cdot 2 \mathrm{kPa})$.

The nomogram is suitable for use up to an altitude of 11000 feet (3353 metres). We recommend that users draw a vertical line corresponding to the barometric pressure at the altitude at which they are working. The line for use at sea level is the one already drawn at $760 \mathrm{~mm} \mathrm{Hg}$. Plotting values on a line that is already drawn increased accuracy.

Our nomogram therefore gives fairly accurate values of $\mathrm{PAO}_{2}$ within a reasonable time. Moreover, its ease of use makes it a convenient alternative to a pocket calculator.

We are grateful to the resident doctors from the department of medicine for their cooperation, and to Peter Gonsalves for helping us to prepare this nomogram.

1 Nunn JF. Applied respiratory physiology. London: Butterworths, 1977:274-310.

West JB. Ventilation-perfusion relationship. Am Rev Respir Dis 1977;116:919-43.

3 Bone RC, Stober G. Mechanical ventilation in respiratory failure. Med Clin North Am 1983;67:599-619.

4 Benator FR, Hewlett AM, Nunn JF. The use of isoshunt lines for control of oxygen therapy. $\mathrm{Br} J$ Anaesthesiol 1973; 45:711-8.

5 Gilbert R, Keighley JF. The arterial/alveolar oxygen tension ratio. An index of gas exchange applicable to varying inspired oxygen concentration. Am Rev Respir Dis 1974;109:142-5.

6 Balk RA, Bone RC. Mechanical ventilation. In: Bone RC, George RB, Hudson LD, eds. Acute respiratory failure. New York: Churchill Livingstone, 1987:213-38.

7 Shapiro BA, Harrison RA, Walton JR. Clinical application of blood gases. 3rd ed. Chicago: Year Book Medical Publishers, 1982:209-27.

8 Apte NM, Karnad DR. Altitude hypoxia and the arterial to alveolar oxygen ratio (letter). Ann Intern Med 1990; 112:547-8.

9 George RB. Pathophysiology of acute respiratory failure. In: Bone RC, George RB, Hudson LD, eds. Acute respiratory failure. New York: Churchill Livingstone, 1987:1-9.

10 Riley RL, Cournand A. Ideal alveolar air and the analysis of ventilation perfusion relationships in the lung. $J$ Appl Physiol 1949;1:825-47. 